\title{
Sentimentos correlacionados a diferentes contingências de reforçamento: uma tarefa experimental com universitários
}

\section{Feelings related to different reinforcement contingencies: an experimental task with university students}

\author{
Mariantonia Chippari* \\ Eliana I. Moraes Hamasaki** \\ Gerson Yukio Tomanari***
}

\begin{abstract}
Resumo
Os sentimentos são concebidos, segundo a perspectiva da análise do comportamento, como eventos privados ou encobertos; ou seja, comportamentos que não são acessíveis à observação pública, mas que devem ser analisados de acordo com os mesmos princípios dos comportamentos públicos. Estudos na área vêm possibilitando a discussão a respeito da relação entre o desempenho em uma determinada tarefa e a descrição que o indivíduo faz da mesma. Assim, o presente estudo teve por objetivo investigar como estudantes universitários submetidos a contingências experimentais, com ganho ou perda de pontos, descreviam os sentimentos e suas opiniões durante uma tarefa de construção de frases. Em um contexto de ensino em análise do comportamento, 111 universitários foram expostos à tarefa informatizada de construir frases. Após o estabelecimento da linha de base, os participantes, em
\end{abstract}

* Psicóloga, Professora do Curso de Psicologia da Universidade Metodista de São Paulo

* Psicóloga, Professora do Curso de Psicologia da Universidade Nove de JulhoUninove, S.P.

*** Psicólogo, professor doutor do Instituto Psicologia da Universidade de São Paulo - USP 
dois diferentes grupos, podiam ganhar (vs. manter) ou manter (vs. perder) pontos, segundo contingências programadas de reforçamento positivo ou negativo, respectivamente, aplicadas ao uso de um pronome previamente selecionado, "nós" ou "ele (a)". Ao final da tarefa, foi disponibilizado para cada participante um questionário requisitando dados pessoais, bem como uma questão referente à atividade realizada e duas escalas do tipo Likert. Os dados obtidos indicaram que os sentimentos não devem ser considerados apenas como uma condição causal ou desencadeadora, e, neste sentido, discute-se sentimentos e emoções como produtos de interação entre operantes e respondentes que podem, assim, alterar a predisposição para a ação.

Palavras-chave: Sentimentos; contingências de reforçamento; análise do comportamento; universitários.

\section{Abstract}

Feelings are conceived from the perspective of behavior analysis as private or covert events; that is, behaviors that are not accessible to public observation, but that should be analyzed according to the same principles of public behavior. Studies in the area have made it possible to discuss the relationship between performance in a given task and the individual's description of it. Thus, the present study had as objective to investigate how university students submitted to experimental contingencies, with gain or loss of points, described their feelings and opinions during a task of sentence construction. In a context of teaching in behavior analysis, 111 college students were exposed to the computerized task of constructing sentences. After the establishment of the baseline, participants in two different groups could gain (vs. maintain) or maintain (vs. lose) points, according to planned contingencies of positive or negative reinforcement, respectively, applied to the use of a previously pronounced pronoun Selected, "we" or "he/she". At the end of the task, a questionnaire requesting personal data was made available to each participant, as well as a question regarding the activity performed and two Likert-type scales. The data obtained indicated that feelings should not be considered only as a causal or triggering condition, and, in this sense, feelings and emotions are discussed as products of interaction between operants and respondents that may, therefore, change the predisposition for action.

Key words: Feelings; reinforcement contingencies; behavior analysis; undergraduate students. 


\section{Introdução}

Uma das críticas mais contundentes feitas à proposta skinneriana é a de que ela ignora os processos internos, tais como o pensamento e a emoção, na interpretação do comportamento humano. Essa é uma crítica que, de acordo com Matos (1997), se fosse aplicável à proposta behaviorista, deveria se remeter ao behaviorismo metodológico de Watson e não à proposta do behaviorismo radical de Skinner. Soma-se a isso o fato de que estamos muito acostumados a ouvir que em comportamos desta ou daquela maneira são tidos por causa de nossos sentimentos; como se o que estivéssemos sentindo fosse o determinante de nosso comportamento. Sendo assim, a emoção passa a ser tida como causa do comportamento.

Deste modo, é interessante lembrar Skinner (1989/1995, p.15) quando expressou que é "fácil confundir o que sentimos como causa, porque nós o sentimos enquanto estamos nos comportando, mas os eventos que são responsáveis pelo que fazemos e, portanto, pelo que sentimos permanecem num passado realmente distante".

Assim, o que é sentido não deve ser tomado como a causa do comportamento, uma vez que a causa estará sempre relacionada à história do organismo sob três níveis:

1. filogenético: história genética, na qual foram selecionadas as características essenciais para a sobrevivência da espécie;

2. ontogenético: história de vida, na qual o ambiente seleciona comportamentos ao longo da existência do indivíduo; e

3. cultural: história das práticas e costumes selecionados pela comunidade da qual o indivíduo faz parte.

Então, o sentimento é definido por Skinner como "um tipo de ação sensorial, assim como ver e ouvir" (1989/1995, p.14). Ao falarmos de sentimento estamos nos referindo a uma relação organismo-ambiente em que determinadas alterações no ambiente são produzidas pelo organismo que, por sua vez, receberá os efeitos dessas alterações. Tais alterações repercutirão sobre a manutenção ou não de determinados comportamentos e, neste sentido, admite-se que a sobrevivência de um comportamento é determinada pelas consequências que poderão fortalecê-lo ou enfraquecê-lo.

Ainda segundo Skinner (1957/1978, p. 15), "os homens agem sobre o mundo, modificam-no e, por sua vez, são modificados pelas 
consequências de sua ação". Estas consequências repercutirão sobre a ocorrência das ações, configurando-se assim, diferentes contingências de reforçamento. Um processo de reforçamento é definido como positivo ou negativo. É definido reforçamento positivo quando a resposta produz uma consequência que determinará o aumento futuro da frequência dessa resposta; por exemplo, tornar-se titular do time (consequência) porque treinou sistemática e assiduamente (respostas). Segundo mesmo autor, quando o nosso comportamento é reforçado positivamente, nós dizemos que gostamos do que estamos fazendo: dizemos que estamos felizes.

Por outro lado, seguindo ainda o raciocínio skinneriano, o reforçamento negativo é definido quando a resposta produz como consequência a remoção de um determinado estímulo que adquiriu função aversiva para o indivíduo. Assim, a frequência da resposta que remove esse estímulo aversivo aumenta. Por exemplo, um aluno que não entrega as atividades solicitadas pelo professor tem como consequência a diminuição de sua nota. Esta consequência (perda da nota integral) para este aluno adquiriu uma função aversiva e, por isso, em situações futuras, esse aluno passará a entregar as atividades solicitadas em dia. Destaca-se, neste caso, que na situação de reforçamento negativo, o evento reforçador é a ausência do estímulo aversivo.

A relação entre o que indivíduo faz e as consequências produzidas por suas ações é da mesma natureza: não há diferença na determinação dos comportamentos públicos e comportamentos privados. Skinner (1989/1995, p. 13) destaca, neste sentido, que "aquilo que as pessoas sentem é tão importante quanto aquilo que elas fazem".

Entender sentimentos apenas como uma condição causal ou desencadeadora é uma simplificação inadequada e este tipo de visão nos afasta do ponto principal que é estudar as contingências envolvidas no contexto de cada indivíduo. Não choramos porque estamos tristes ou sentimos tristeza porque choramos; choramos e sentimos tristeza porque alguma coisa aconteceu, como por exemplo, a perda de uma pessoa querida. Na visão skinneriana “a prática de buscar dentro do organismo uma explicação para o comportamento tende a obscurecer as variáveis que estão disponíveis de forma imediata. Estas variáveis encontram-se fora do 
organismo, em seu ambiente e em sua história ambiental" (SKINNER, 1974/2006, p.31).

Entende-se por eventos privados ou encobertos, de acordo com Skinner (op. cit.), comportamentos não acessíveis à observação pública, mas que devem ser analisados de acordo com os mesmos princípios dos comportamentos públicos. Neste sentido, é entendido como um evento de dimensões físicas e que, portanto, também se relaciona a contingências de reforçamento inseridas no ambiente tanto físico como social; uma maneira de termos acesso às respostas encobertas seria por meio do comportamento verbal.

O comportamento verbal é um operante, condicionado pela comunidade verbal à qual o indivíduo pertence, porém diferencia-se dos demais operantes pelo fato do reforço ser provido por um ouvinte também condicionado para isso. Nesse sentido, o comportamento verbal não se limita unicamente a comportamentos vocais; há vários tipos de comportamentos verbais que são classificados pelas relações que os mesmos estabelecem entre o que se denominam respostas e estímulos de controle. O comportamento verbal (SKINNER, 1957/1978) permite que façamos descrições das contingências que controlam outros comportamentos, o que facilita a tomada de consciência das ações de um indivíduo.

Em termos empíricos temos detectado que quando os pesquisadores não obtêm dados de observação sobre as respostas que estão investigando, como, por exemplo, os sentimentos, se utilizam de relatos verbais dos sujeitos para tentar descrever as contingências que estão provavelmente operando naquela situação (DE ROSE , 1997).

De acordo com Souza (1997), ao conhecermos as relações resposta/estímulo reforçador, bem como os tipos de reforços e seus esquemas, poderemos entender o que motiva os indivíduos a se comportarem da maneira como se comportam, bem como as diferentes influências desses reforços.

Uma revisão da literatura, ainda que não exaustiva, aponta poucos trabalhos com esta temática. Um desses trabalhos foi conduzido por Hamasaki (2003) que verificou a influência de diferentes condições de reforçamento sobre o desempenho de estudantes em uma tarefa de construção de frases e utilizou um programa de computador Verbal 2.0, elaborado por Carvalho, Góes e Tomanari 
(2001). Tal programa consistia em apresentar sucessivamente verbos no infinitivo (representar, mandar, gostar etc.) na parte central da tela, acompanhada por três listas do tipo drop-down ${ }^{1}$ alinhadas horizontalmente, logo abaixo do verbo. Cada lista correspondia da esquerda para a direita: pronomes do caso reto [eu, tu, ele (a), nós, vós, eles (as)]; o verbo conjugado (de acordo com a escolha anterior, o que impossibilita o erro gramatical do participante na conjugação) e complemento (uma seleção de advérbios: bem, muito, mais, dentre outros e adjetivos: calado, contente, feliz, dentre outros). Ao final de toda a construção da frase, o participante deveria clicar "ok" na parte inferior da tela. Para o reforçamento diferencial foram selecionados os pronomes "ele" (a) para um grupo e "nós" para outro. Assim, dependendo das condições de reforçamento, apareciam indicadores de ganho/manutenção ou perda/manutenção de pontos na tela do computador, tornando possível à visualização do total de pontos ao término de cada frase. A pesquisa conduzida por Hamasaki (2003) mostrou que independentemente da condição de reforçamento a qual o participante estava submetido, houve um aumento na frequência do pronome selecionado para o reforçamento diferencial.

Os dados obtidos por esse estudo possibilitam a discussão a respeito da relação entre o desempenho em uma determinada tarefa e a descrição que o indivíduo faz da mesma. Por exemplo, se ao indivíduo submetido a uma tarefa tal como a descrita acima, for possível a identificação das contingências sob as quais estava efetivamente submetido, tornar-se-ia mais provável a descrição dessas contingências e, também, dos sentimentos e emoções envolvidos.

O presente estudo se fundamenta a partir dessa discussão e em uma replicação sistemática de Hamasaki (2003), introduz questões aos participantes para que os mesmos possam descrever a tarefa e os sentimentos envolvidos.

Diferentes contingências, envolvendo reforçamento positivo ou negativo, nos remetem à seguinte questão: como estudantes universitários, submetidos a uma determinada tarefa planejada de

Lista drop-down é uma estrutura de tela que, quando clicada, exibe ao usuário uma lista de opções. Ao se clicar sobre uma destas opções, a lista se recolhe, passando a exibir o texto da opção escolhida. 
laboratório, descrevem seus sentimentos a partir das consequências produzidas na tarefa; isto é, de ganhar ou perder pontos?

Deste modo, o presente estudo teve por objetivo geral: investigar como estudantes submetidos a contingências experimentais, com ganho ou perda de pontos, descreviam os sentimentos e opiniões durante uma tarefa de construção de frases.

\section{Método}

Participantes - fizeram parte deste estudo 111 universitários de uma universidade privada da região do $\mathrm{ABC}$ paulista. $\mathrm{O}$ critério estabelecido na escolha dos participantes foi o de que esses não tivessem entrado em contato com conceitos da análise experimental do comportamento (AEC). Os participantes foram divididos em dois grupos, de acordo com as contingências em vigor: se contingência de ganho de pontos, o participante pertencia ao grupo denominado G; se contingência de perda de pontos, o participante pertencia ao grupo denominado P. O número de participantes nas contingências G e P foram, respectivamente, 59 e 52.

Materiais e Instrumentos: para a coleta de dados foram utilizados: a) 40 computadores marca LINCE, Pentium I; b) um programa Verbal 2.0 (TOMANARI; PAVÃO; BENASSI, 2003); c) questionário contendo uma questão aberta e d) duas escalas do tipo Likert.

Local: o experimento foi realizado no laboratório de informática. A coleta dos dados foi realizada coletivamente, sendo que, na sala com os participantes, estavam os experimentadores e um monitor responsável pelo laboratório.

Procedimento: inicialmente, a sala de informática foi preparada para que todos os computadores apresentassem a tela com a primeira mensagem de instrução para o início da tarefa. Os participantes foram instruídos a não ficarem sob o controle do que acontecia no computador dos demais colegas, com a informação de que o que acontecia com outros participantes não necessariamente aconteceria com ele. Após isso, a sessão foi iniciada.

Os participantes foram divididos em dois grupos. Para um grupo, o pronome selecionado para receber a consequência diferencial foi o NÓs; enquanto para o outro grupo, o pronome ELE (A) foi o selecionado para receber a consequência diferencial. A programação 
das consequências diferenciais foi: a adição; a subtração ou a manutenção de pontos previamente adquiridos ou atribuídos inicialmente, tal como especificado no Quadro 1. Os grupos foram especificados pelas siglas: P: grupo submetido à condição perda de pontos; e G: grupo submetido à condição ganho de pontos.

Quadro 1: Sumário dos grupos de participantes com indicação das duas condições experimentais.

\begin{tabular}{|c|c|c|c|c|}
\hline & \multirow{2}{*}{ Pronome } & \multicolumn{3}{|c|}{ PONTOS } \\
\cline { 3 - 5 } & Selecionado & Iniciais & $\begin{array}{c}\text { Pronome Sele- } \\
\text { cionado }\end{array}$ & $\begin{array}{c}\text { Outros } \\
\text { Pronomes }\end{array}$ \\
\hline $\mathrm{P}$ & $\begin{array}{c}\text { NÓS ou } \\
\text { ELE (a) }\end{array}$ & 600 & 0 (time-out) & -10 \\
\hline$G$ & $\begin{array}{c}\text { NÓS ou } \\
\text { ELE (a) }\end{array}$ & 0 & +10 & 0 (time-out) \\
\hline
\end{tabular}

A configuração de cada grupo de participantes era indicada previamente nos computadores para a realização da tarefa.

Na tela do computador, apareceram as seguintes mensagens que deveriam ser lidas pelos participantes para o início da tarefa:

\section{Mensagem 1 (a todos os participantes do grupo G):}

“O propósito deste experimento é verificar como as pessoas constroem frases. Ele não envolve avaliação de inteligência ou de personalidade.

"Nesta tela do computador vai aparecer uma série de verbos no infinitivo (isto é, sem ser conjugados, por exemplo, latir, voar, acelerar e assim por diante). Os verbos serão apresentados um a um. Para cada um deles, você deverá construir uma frase".

"Para isso, comece escolhendo um pronome para iniciar a sua frase; a seguir, escolha um verbo e, depois, um complemento. Por fim, leia a frase que você construiu e clique com o mouse sobre o botão CONFIRMA".

"Em sua tarefa, você GANHARÁ pontos. Seus pontos aparecerão, a partir de certo momento, na parte superior do vídeo" 
"QUANTO MAIS PONTOS VOCÊ OBTIVER, MELHOR"

"Você entendeu? Está pronto para começar?"

\section{Mensagem 2 (a todos os participantes do grupo P):}

“O propósito deste experimento é verificar como as pessoas constroem frases. Ele não envolve avaliação de inteligência ou de personalidade".

"Nesta tela do computador vai aparecer uma série de verbos no infinitivo (isto é, sem ser conjugados, por exemplo, latir, voar, acelerar e assim por diante). Os verbos serão apresentados um a um. Para cada um deles, você deverá construir uma frase".

"Para isso, comece escolhendo um pronome para iniciar a sua frase; a seguir, escolha um verbo e, depois, um complemento. Por fim, leia a frase que você construiu e clique com o mouse sobre o botão CONFIRMA".

“Em sua tarefa, você PERDERÁ pontos. Seus pontos aparecerão, a partir de certo momento, na parte superior do vídeo"

"QUANTO MAIS PONTOS VOCÊ MANTIVER, MELHOR"

"Você entendeu? Está pronto para começar?"

Assim, se após a leitura das instruções, o participante pedisse mais esclarecimentos, os experimentadores se limitavam a ler as instruções novamente, sem fazer qualquer outro comentário. Com a compreensão das instruções pelos participantes, a sessão foi iniciada com a apresentação do primeiro verbo.

Durante a sessão experimental foram apresentados 72 verbos divididos em seis blocos de 12 verbos cada um. O primeiro bloco correspondia à linha de base; portanto, não importava qual o pronome utilizado pelo participante, o computador não apresentava, ao final da frase elaborada, qualquer consequência diferencial (ganho ou perda de pontos). O objetivo desse bloco foi verificar a frequência de utilização de cada pronome pelos participantes. Para os demais blocos, o computador começava a liberar as consequências diferenciais, em função do pronome usado.

Após o participante ter construído as 72 frases, a sessão foi finalizada. $\mathrm{O}$ computador apresentava a seguinte mensagem: 
“Você chegou ao final da sessão. Muito obrigado pela sua participação. O experimentador está à sua disposição para lhe fornecer esclarecimentos e tirar qualquer dúvida sobre este estudo. Por favor, mantenha-se em silêncio, aguardando até que todos os seus colegas encerrem o trabalho"

As informações obtidas na tarefa foram registradas, possibilitando a visualização e compilação dos dados posteriormente. Ao final da tarefa, foi disponibilizado para cada participante um questionário requisitando dados pessoais, bem como uma questão referente à atividade realizada e as duas escalas.

\section{Resultados e discussão}

O procedimento da presente investigação conduziu um experimento com comportamento humano sob as diferentes contingências em condições relativamente comparáveis, de maneira considerada eticamente aceitável, uma vez que a consequência era a perda de pontos atribuídos à tarefa executada. Lembrando que se buscou descrever como pessoas submetidas a contingências experimentais nas quais a tarefa de construção de frases produzia o ganho de pontos (G) ou a perda de pontos $(\mathrm{P})$, a depender do pronome utilizado; e como os participantes descreviam os sentimentos e opiniões em relação à tarefa executada, ao final da mesma.

Em geral a preocupação em experimentos que pretendem comparar contingências de reforçamento positivo e negativo lidam com o que se denomina "comparabilidade" das consequências em termos de sua natureza (CRITCHFIELD; MAGOON, 2001). No caso desta proposta, as consequências são consideradas comparáveis, neste sentido, pois, a variável "pontos" era adicionada, mantida ou subtraída.

Observa-se, na Figura 1, o desempenho dos participantes na tarefa em função de cada condição de reforçamento, aqui nomeadas: contingências G e P. Cada um dos seis blocos apresenta o percentual de respostas relativas a 12 frases. $O$ primeiro bloco refere-se à Linha de Base (LB) e, nele, observa-se que, para as duas condições de reforçamento, houve uma frequência semelhante ao uso dos pronomes: $26,8 \%$ e $27,2 \%$, respectivamente. 
Figura 1: Percentual do uso de pronomes ao longo dos blocos de tentativas.

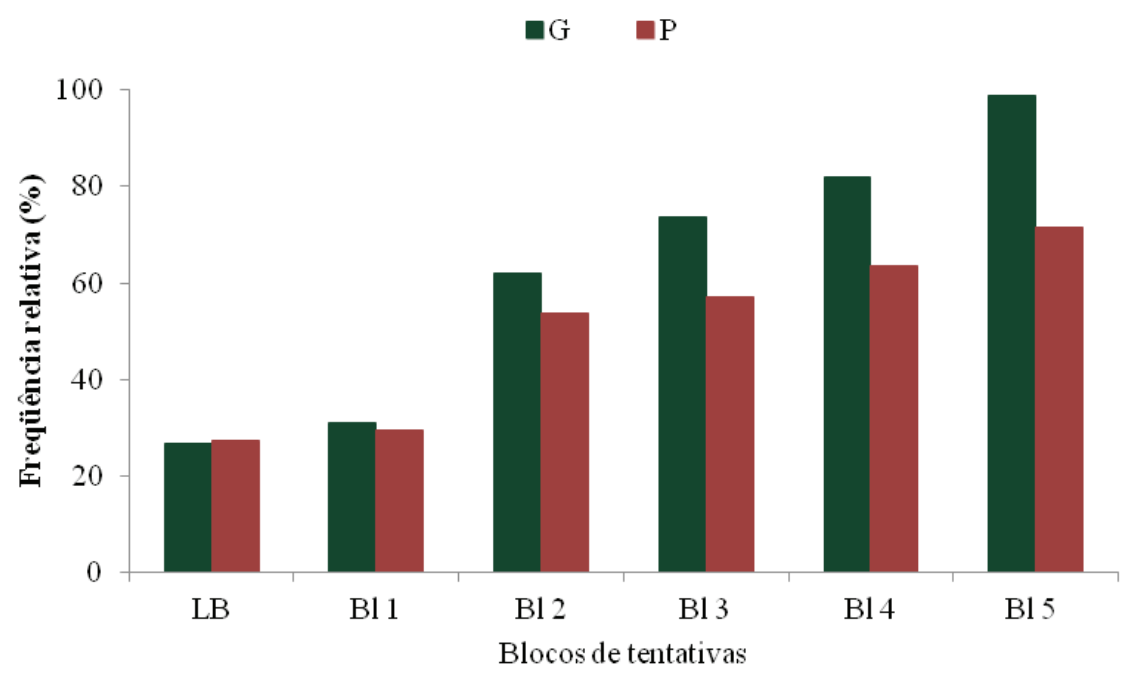

Nos blocos nos quais a manipulação experimental foi introduzida (Blocos 1 a 5), verificou-se que, em ambas as contingências, o desempenho apresentado na tarefa pelos participantes aumentou gradativamente em frequência em todos os blocos, com exceção do Bloco 1. Destaca-se, entretanto, a constante diferença em relação ao percentual de uso dos pronomes quando comparadas as duas contingências, prevalecendo o maior uso entre os participantes submetidos à contingência G. No último bloco, por exemplo, o percentual atingido pelos participantes da contingência $G$ foi $98,7 \%$ e da contingência $P$ foi $71,6 \%$.

Dentro dos limites do presente experimento, a contingência de reforçamento positivo comparada à contingência de reforçamento negativo, foi acompanhada de maior aumento da frequência do uso do pronome selecionado para a consequência diferencial [ELE (a) ou NÓS].

Sob a condição na qual o indivíduo produz consequências reforçadoras positivas por meio de suas ações, Skinner (1969) admite que o efeito, em termos de sentimento, é o que aprendemos a nomear de felicidade e de bem estar. Isto é, dizemos que gostamos de fazer determinada coisa porque a consequência produzida nos deixa feliz. 
Ainda levando em consideração a questão da comparabilidade das diferentes contingências, a presente proposta também investigou quais sentimentos estavam envolvidos na tarefa.

A Tabela 1 apresenta os indicadores do que foi qualificado como sentimentos descritos pelos participantes da contingência G. Foram registrados 121 adjetivos espontâneos, organizados em três categorias:

1. Sentimentos positivos, que corresponderam a $41,3 \%$ dos adjetivos, sendo que entre eles os mais frequentes foram interessante, $11,6 \%$; curioso $8,3 \%$ e agradável $7,4 \%$;

2. Sentimentos negativos tiveram frequência de $34,6 \%$, sendo: cansativo, $14,9 \%$; duvidoso, $8,3 \%$ e repetitivo, $2,5 \%$; e

3. Sentimentos neutros $2,5 \%$, sendo: simples $1,7 \%$ e diferente $0,8 \%)$.

Foram excluídas $21,4 \%$ das respostas nas quais os participantes não descreveram os sentimentos por meio de adjetivos.

Tabela 1: Distribuição dos indicadores (adjetivos) descritos na contingência $G$.

\begin{tabular}{|c|c|c|c|c|c|c|c|}
\hline \multicolumn{8}{|c|}{ Sentimentos } \\
\hline Positivos & $\%$ & Negativos & $\%$ & Neutros & $\%$ & Outros & $\%$ \\
\hline Interessante & 11,6 & Cansativo & 14,9 & Simples & $1,7 \%$ & \multirow[b]{2}{*}{ Excluídos } & \multirow[b]{2}{*}{21,4} \\
\hline Curioso & 8,3 & Duvidoso & 8,3 & Diferente & $0,8 \%$ & & \\
\hline Agradável & 7,4 & Repetitivo & 2,5 & & & & \\
\hline Legal & 4,1 & Entediante & 1,7 & & & & \\
\hline Bom & 2,5 & Ansioso & 0,8 & & & & \\
\hline Paciente & 2,5 & Demorada & 0,8 & & & & \\
\hline Fácil & 1,7 & Irritada & 0,8 & & & & \\
\hline Clara & 0,8 & Difícil & 0,8 & & & & \\
\hline Confiante & 0,8 & Agitada & 0,8 & & & & \\
\hline Ótima & 0,8 & Inquieta & 0,8 & & & & \\
\hline \multirow[t]{3}{*}{ Proveitosa } & 0,8 & Apreensiva & 0,8 & & & & \\
\hline & & $\begin{array}{c}\text { Desinteres- } \\
\text { sante }\end{array}$ & 0,8 & & & & \\
\hline & & Impaciente & 0,8 & & & & \\
\hline Total & 41,3 & & 34,6 & & 2,5 & & 21,4 \\
\hline
\end{tabular}


Admitindo o sentimento de felicidade tal como definido anteriormente, pode-se entender que "(...) os homens são felizes em um meio ambiente no qual o comportamento ativo, produtivo e criativo é reforçado de forma efetiva" (SKINNER, 1969, p.4).

Além do sentimento de felicidade, admite-se que, sob essas condições, o indivíduo sente-se mais confiante; pois, a confiança está baseada na segurança e na certeza de que será bem sucedido (SKINNER, 1974/2006).

Os dados ilustrados na Tabela 2 (na página seguinte) referem-se à contingência $\mathrm{P}$ quanto aos indicadores de sentimentos. Nesta, os participantes descreveram 102 adjetivos espontâneos (20\% menor do que na contingência $G$ ), distribuídos nas mesmas categorias utilizadas anteriormente, com exceção da categoria sentimentos neutros, uma vez que estes não foram descritos. Os sentimentos positivos foram descritos em $27,5 \%$ do total de respostas e, dentre esses, destacaram-se os adjetivos: interessante e curioso, ambos com 7,8\%.

A categoria sentimentos negativos apresentou um percentual de $49,3 \%$, com destaque a dois indicadores: duvidoso e cansativo, com o percentual de $13,7 \%$ para ambos. As respostas excluídas, segundo o critério adotado, totalizaram $22,6 \%$.

Um ponto a destacar a respeito desses dados refere-se à questão de o interesse sobre algo que a pessoa faz ser diretamente relacionada à consequência produzida. Por exemplo, quando uma pessoa está empenhada em uma conversa animada pode deixar de falar com todo o vigor que tinha apresentado na conversa ou até parar de falar se, porventura, alguém que a tratou de forma adversa se aproximar (SKINNER, 1974/2006).

Destacam-se os adjetivos descritos pelos participantes sob a condição P e que qualificam a tarefa negativamente e, não raro, com expressões de enfado (por exemplo: lento; chato; decepcionante; (dês) prazeroso; cansativo e duvidoso). Ao passo que, entre os participantes sob a condição $\mathrm{G}$, os adjetivos qualificam a tarefa com expressões de interesse à mesma (por exemplo: interessante; curioso; agradável e legal).

Pode-se observar que, enquanto na contingência G, a diferença entre o percentual de sentimentos positivos (41,3\%) e negativos $(34,7 \%)$ totaliza 6,6\%; na contingência $P$, essa diferença foi maior: $24 \%$. 
Tabela 2: Distribuição dos indicadores (adjetivos) descritos na contingência $P$.

\begin{tabular}{|c|c|c|c|c|c|}
\hline \multicolumn{6}{|c|}{ Sentimentos } \\
\hline Positivos & $\%$ & Negativos & $\%$ & Outros & $\%$ \\
\hline Interessante & 7,8 & Cansativo & 13,7 & \multirow{2}{*}{ Excluídas } & \multirow[b]{2}{*}{22,6} \\
\hline Curioso & 7,8 & Duvidoso & 13,7 & & \\
\hline Agradável & 6,9 & Raiva & 2,0 & & \\
\hline Paciente & 2,0 & Nervoso & 2,0 & & \\
\hline Legal & 1,0 & Ansioso & 5,9 & & \\
\hline Orgulhoso & 1,0 & Demorada & 2,0 & & \\
\hline \multirow[t]{10}{*}{ Fácil } & 1,0 & Repetitivo & 1,0 & & \\
\hline & & Perdida & 1,0 & & \\
\hline & & Inseguro & 1,0 & & \\
\hline & & Lento & 1,0 & & \\
\hline & & Chato & 1,0 & & \\
\hline & & Difícil & 1,0 & & \\
\hline & & Desprazeroso & 1,0 & & \\
\hline & & Decepcionante & 1,0 & & \\
\hline & & Confuso & 1,0 & & \\
\hline & & Exaustivo & 1,0 & & \\
\hline Total & 27,5 & & 49,3 & & 22,6 \\
\hline
\end{tabular}

Foram utilizadas, ainda, duas escalas do tipo Likert, ambas compostas por sete indicadores que, por sua vez, apresentavam sete graduações (de 1 a 7). A primeira escala solicitava que o participante indicasse seus sentimentos e, a segunda, sua opinião a respeito da tarefa utilizada.

Utilizou-se para o cálculo do percentual das respostas, o seguinte critério: foi realizada uma somatória correspondente a cada uma das graduações escolhidas por cada participante. Posteriormente, foi dividido o resultado pelo número de respostas. No caso do participante ter respondido a todos os indicadores, realizou-se a somatória destes, segundo a graduação escolhida. Por exemplo: 33 pontos seriam divididos pelo número de indicadores, no caso 
sete, chegando a uma média de 4,8 na escala correspondente. Caso não escolhesse todos e escolhesse apenas o que classificava a tarefa como desconfortável / confortável, pontuando a graduação "6", seria dividido pelo número de indicadores escolhidos, no caso 1, que resultava como média, 6 .

Após o cálculo da média para cada escala (sentimento e opinião) de cada participante do grupo, as médias foram classificadas numa ordem crescente. Médias até 2,99 foram categorizadas como negativas, ou seja, indicavam sentimentos ou opiniões negativas; de 3 a 3,99 foram categorizadas como sentimentos ou opiniões neutros e de 4 até 7 foram categorizadas como positivas.

A Figura 2 apresenta a distribuição dos sentimentos descritos pelos participantes frente à tarefa executada sob as contingências $G$ e P. Os sentimentos foram frequentemente positivos, 71,08\%, para os participantes sob a contingência G e 61,04\% para P. As avaliações categorizadas neutras apresentaram maior frequência na contingência $P, 22,08 \%$, em comparação à $G, 16,87 \%$. Observa-se sutil diferença entre as avaliações negativas nas diferentes contingências: 12,0 \% (G) e $16,9 \%(P)$.

Figura 2: Distribuição dos sentimentos, segundo as categorias determinadas.

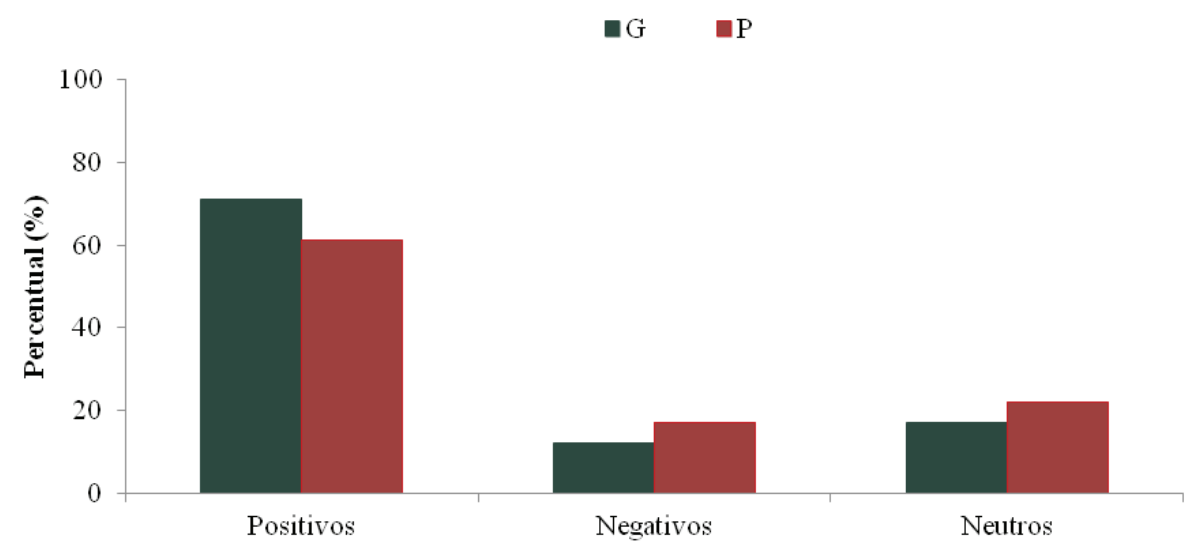

Qualificação dos sentimentos 
Embora com menor ênfase em relação aos dados obtidos pelo questionário, os dados produzidos pelas escalas corroboram àqueles; pois, a condição $G$ apresenta-se melhor avaliada (maior frequência de sentimentos positivos) do que a condição P (maior frequência de sentimentos negativos e neutros).

Essa mesma avaliação, observada na Figura 3, repete-se quanto às opiniões dos participantes em relação à tarefa sob as duas contingências: $G$ e $P$.

Figura 3: Distribuição das opiniões, segundo as categorias determinadas.

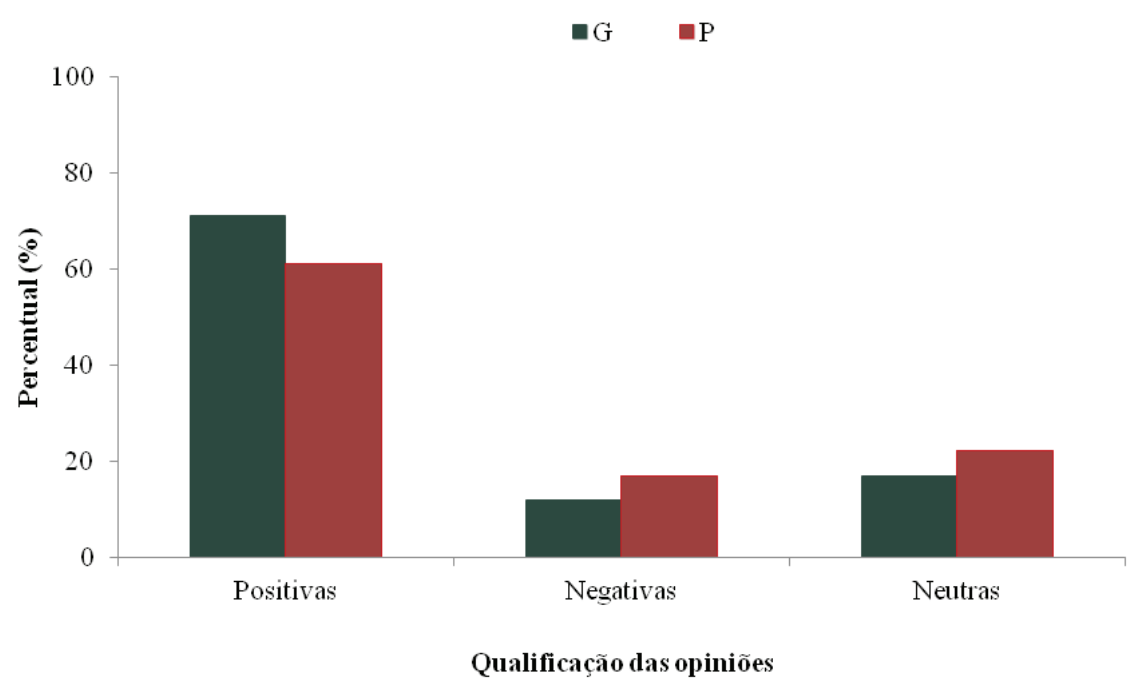

Destaca-se (nessa fig. 3) que a tarefa recebeu avaliação positiva para $71,93 \%$ dos participantes que estavam sob a contingência G e $60,53 \%$ dos participantes sob a contingência P. Nesta, as opiniões a respeito da tarefa sob as categorias neutras e negativas apresentaram, respectivamente, frequências de $26,32 \%$ e $13,16 \%$ e, na contingência $\mathrm{G}, 12,05 \%$ e 6,02\%.

Os dados, aqui apresentados, contribuem com a concepção de que os sentimentos não devem ser considerados apenas como uma condição causal ou desencadeadora; pois, esta é uma simplificação porque nos distancia do ponto principal que é estudar as contingências envolvidas no contexto de cada indivíduo. 
Sentimentos, e também as emoções, são considerados, pela análise do comportamento, comportamentos complexos porque não devemos perder de vista que os mesmos são produtos da interação entre comportamentos operantes e comportamentos respondentes.

Neste caso, deve-se atentar para as relações entre os estímulos antecedentes e consequentes porque classes de estímulos antecedentes passam a evocar respostas funcionalmente semelhantes e produtoras de consequências específicas (SKINNER, 1974/2006).

Nestas relações, os estímulos antecedentes passam a ter três funções:

1. Discriminativa (ocasião "sinalizadora" de reforçamento);

2. Reforçadora condicionada (maior probabilidade de ocorrência de respostas sob sua presença); e

3. Eliciadora (em uma relação respondente $=S \rightarrow R$ ).

Assim, conclui-se, como destaca Thomaz (2012), que emoções e sentimentos podem alterar a predisposição para a ação. Por exemplo: uma pessoa que perdeu um jogo em função de um erro do árbitrodirá que "está com raiva". Esse sentimento (a raiva), segundo a análise do comportamento, pode ser expresso por:

(a) Alta frequência de respostas produtoras de dano ao outros [s] (xingar; reclamar; gritar e socar);

(b) Respostas reflexas (aumento dos batimentos cardíacos; enrubescimento; ofegar) eliciadas pela punição/extinção característica da condição da perda do jogo; e

(c) Diminuição da efetividade reforçadora de outros estímulos (presença da família) e aumento da probabilidade de comportamentos de isolamento.

Em síntese, considera-se a importância de destacar que buscar "dentro do organismo" uma explicação para o comportamento não contribui para a compreensão de fenômenos complexos, tais como os sentimentos, pois essa prática tende a obscurecer as variáveis que estão disponíveis de forma imediata. E estas variáveis, na visão skinneriana, encontram-se "fora do organismo", em seu ambiente e em sua história ambiental (SKINNER, 1953/1994). 


\section{Referências}

CARVALHO, A.; GÓES, Z.; TOMANARI, G.Y. O comportamento verbal sob controle pelas consequências. In: X ENCONTRO BRASILEIRO DE DE PSICOTERAPIA E MEDICINA COMPORTAMENTAL, 10, 2001. Resumos de Comunicação Científica do X Encontro Brasileiro de psicoterapia e medicina comportamental ABPMC, Campinas: Associação Brasileira de psicologia e Medicina Comportamental, 2001, p. $43-44$.

CRITCHFIELD, T.S.; MAGOON, M.A. On the differential impact of positive and negative reinforcement. Experimental Analysis of Human Behavior Bulletin, n.19, p. 16-18, 2001.

DE ROSE, J.C.C. O relato verbal segundo a perspectiva da análise do comportamento: Contribuições conceituais e experimentais. In: BANACO, R. A. (Org.). Sobre Comportamento e Cognição, Vol. I. Santo André: ARBytes, 1997, p.148-166. HAMASAKI, E.I.M. Efeitos de diferentes contingências de reforço sobre o uso de pronomes e tempos verbais na construção de frases. 150f. Dissertação (Mestrado) - Departamento de Psicologia Experimental, Instituto de Psicologia, Universidade de São Paulo, São Paulo, 2003.

MATOS, M. A. O behaviorismo metodológico e suas relações com o mentalismo e o behaviorismo radical. In: BANACO, R. A. (Org.). Sobre comportamento e cognição. Vol. I. Santo André: ARBytes, 1997, p.54-67.

SKINNER, B.F. Ciência e comportamento humano. São Paulo: Martins Fontes, 1994. (Original publicado em 1953).

SKINNER, B.F. Sobre o behaviorismo. São Paulo: Cultrix, 2006. (Original publicado em 1974).

SKINNER, B.F. O comportamento verbal. São Paulo: Cultrix, 1978. (Original publicado em 1957).

SKINNER, B.F. Questões recentes na análise comportamental. Campinas: Papirus, 1995. (Original publicado em 1989).

SKINNER, B.F. Contingencies of reinforcement: A theoretical analysis. New York: Appleton-Century-Crofts, 1969.

SOUZA, D.G. O que é contingência? In: BANACO, R. A. (Org.). Sobre comportamento e cognição, Vol. I. Santo André: ARBytes, 1997, p. 82-87.

THOMAZ, C.R.C. Episódios emocionais como interações entre operantes e respondentes. In: BORGES, N.B; CASSAS, F.A. (Orgs.) Clínico analítico comportamental: 
aspectos teóricos e práticos. Porto Alegre: Artmed, 2012. p. 40-48.

TOMANARI, G.Y.; PAVÃO, I.; BENASSI, M.T. Verbal 2.0: Um programa de computador para estudos experimentais do comportamento verbal sob controle pelas consequências. In: BRANDÃO, F.C.S et al. (Orgs.). Sobre comportamento e cognição. Vol. 12. Santo André: ESETec, 2003. p.379-387.

Contato dos autores:

Mariantonia Chippari: email - marqiantonia.chippari@metodista.br

Universidade Metodista de São Paulo, Universidade Metodista de São Paulo. Rua Dom Jaime de Barros Câmara, 1000, Planalto 09895-400 - Sao Bernardo do Campo, SP - Brasil

Eliana I. Moraes Hamasaki: http://lattes.cnpq.br/2996881299006643

Universidade Nove de Julho, Diretoria da Saúde III. Avenida Doutor Adolpho Pinto, 109, Barra Funda 01156050 - São Paulo, SP - Brasil

Gerson Yukio Tomanari: http://lattes.cnpq.br/5462123484542215

Universidade de São Paulo, Instituto de Psicologia Avenida Professor Mello Moraes, 1721, Butantã 05508030 - São Paulo, SP - Brasil

Recebido em: 13/02/2016

Aceito em: 22/08/2016 